Article

\title{
Here, There, and Everywhere: Applying Vignettes to Investigate Appraisals of Job Demands
}

\author{
Benedicte Langseth-Eide ${ }^{*}$ and Joar Vittersø
}

Department of Psychology, UiT The Arctic University of Norway, 9019 Tromsø, Norway; joar.vitterso@uit.no

* Correspondence: benedicte.langseth-eide@uit.no

check for updates

Citation: Langseth-Eide, B.; Vittersø, J. Here, There, and Everywhere: Applying Vignettes to Investigate Appraisals of Job Demands. Sustainability 2021, 13, 11662. https:/ / doi.org/10.3390/su132111662

Academic Editors: Caterina Gozzoli and Diletta Gazzaroli

Received: 9 September 2021

Accepted: 20 October 2021

Published: 21 October 2021

Publisher's Note: MDPI stays neutral with regard to jurisdictional claims in published maps and institutional affiliations.

Copyright: (c) 2021 by the authors. Licensee MDPI, Basel, Switzerland. This article is an open access article distributed under the terms and conditions of the Creative Commons Attribution (CC BY) license (https:// creativecommons.org/licenses/by/ $4.0 /)$.

\begin{abstract}
The job characteristics literature has revealed that job demands can be differentiated into hindrance and challenge demands. However, there has been little consensus on this categorization. Additionally, studies have revealed that job demands can be perceived as hindering and challenging at the same time. The present study aims to bring nuance to this topic by investigating two job demands (i.e., time pressure and emotionally demanding situations) and to what degree they are appraised as challenging and hindering for two occupational groups (i.e., nurses and real estate agents). This study also investigates the impact of emotional dispositions on demand appraisals. A convenience sample ( $N=851$ Norwegian students) read vignettes and reported their appraisals for six different job situations. A factor analysis revealed that our measures of demand appraisals differed from those reported in previous studies. We therefore labeled the two kinds of appraisals as hindrance-like and challenge-like since they overlap without being identical to the previously reported labels of hindrance and challenge, respectively. Furthermore, we found that job demands were appraised as hindrance-like and challenge-like at the same time but to different degrees. Job demands for core tasks were typically appraised as more challenge-like than hindrance-like. Job demands for non-core tasks were typically appraised as more hindrance-like than challenge-like. Positive trait emotions predicted challenge-like appraisals. By documenting how imagined job demands appear as hindrances and challenges, our study supports previous studies showing that challenge-like demands may play a role in the motivational process in the job demands-resources model. Limitations to vignette studies are discussed.
\end{abstract}

Keywords: job demands; challenge appraisal; hindrance appraisal; JD-R model; vignette studies

\section{Introduction}

The job-demands (JD-R) model [1,2] proposes that working conditions initiate two distinct processes that lead to well-being and ill-being at work. Specifically, job resources start a motivational process that leads to engagement and positive outcomes, whereas job demands start a health impairment process that leads to burnout [3], workaholism [4,5], and negative outcomes. Thus, job demands are positioned as predictors in the health impairment process but have no roles in the motivational process. However, it has been argued that job demands can also be motivating. For example, LePine, Podsakoff, and LePine [6], as well as Podsakoff, LePine, and LePine [6] made a distinction between hindrance and challenging demands, in which hindrance demands have a negative impact and challenge demands have a positive impact on employee well-being, respectively. In their paper, in which they summarize the development of the JD-R theory and address issues that need to be solved, Bakker and Demerouti [2] specifically raise the concern about the two types of job demands (i.e., with a positive or negative impact on well-being) and suggest that new research may try to uncover the conditions under which job demands act as challenges versus hindrances.

The JD-R model states that several job resources and job demands should be grouped into general higher-order factors of resources or demands. However, some studies have 
suggested that job demands may not always belong to one overarching construct. For example, Luchman and González-Morales [7] found that a model, in which several job demands were included as individual factors, fit the data better. It is possible that this finding is due to the notion that demands can be differentiated into demands that have a positive or negative impact (i.e., challenge or hindrance) on employee well-being. Additionally, the confirmatory factor analyses reported in the study of Van den Broeck and De Cuyper [8] supported the differentiation between job hindrances and job challenges. Additionally, structural equation-modeling revealed that job challenges were positively associated with vigor and were unrelated to exhaustion, while job hindrances were positively related to exhaustion and negatively related to vigor. Furthermore, Searle and Auton [9] found that even when the effects of demands were accounted for, it was the individual differences in the appraisal of the demands that consistently explained the unique variance in the outcomes (i.e., affective states). Webster and Beehr [10] revealed that although a demand was primarily perceived as either challenging or hindering, it could also be perceived as both challenging and hindering at the same time. Taken together, this suggests that more research is necessary to clarify the role and denomination of job demands by investigating them in various jobs and work situations, and by assessing how individual characteristics influence appraisals of job demands.

\subsection{Differentiation of Job Demands}

LePine, Podsakoff, and LePine [6], as well as Podsakoff, LePine, and LePine [6] introduced the differentiation of job stressors into challenge stressors and hindrance stressors. Hindrance job stressors have been defined as "job demands or work circumstances that involve excessive or undesirable constraints that interfere with or inhibit an individual's ability to achieve valued goals" ([11], p. 67). This description corresponds with the definition of job demands described in the JD-R model, which describe it as "physical, psychological, social, or organizational aspects of the job that require sustained physical and/or psychological (i.e., cognitive or emotional) effort" ([12], p. 296). Examples of hindrance job demands reported in previous studies include role ambiguity (e.g., $[13,14])$ and illegitimate work tasks (e.g., [15]). These job stressors are considered negative. Conversely, stressors that have the potential to promote personal growth as well as goal achievement are defined as challenge stressors [6]. Examples of challenge stressors reported in the literature include high workload levels (e.g., [16]) and responsibility (e.g., [17]). These demands, although they require effort, may lead to beneficial individual and organizational outcomes, and are therefore considered stressors with positive potential.

It is not yet known whether the differentiation between job demands as challenging and hindering is valid due to the lack of evidence regarding this issue. Moreover, it is still unclear whether such a differentiation between job demands is valid for every occupation [18]. For example, some studies have classified role conflict as a hindrance demand [19], while others have considered it a challenge demand [20]. Similarly, emotional demands have been considered a hindrance demand by some $[21,22]$ and a challenge demand by others [23]. Hence, regarding job demands, the observations, opinions, categorization, and conclusions are not always the same in the scientific literature, and the same job demands are not consistently classified as either hindrances or challenges. Furthermore, it has been shown that employees will not always experience job demands as either hindrances or challenges; indeed, several researchers have argued that the categorization of job demands into being either a hindrance or challenge demand is too simplistic (e.g., [24,25]). A more fruitful approach to the hindrance-challenge framework of job demands may be to investigate the degree to which employees experience job demands as hindering and challenging at the same time. For example, Bakker and Sanz-Vergel [18] showed that nurses perceived work pressure more as a hindrance than as a challenge demand. This approach in which employees report the degree to which they experience each job demand as hindering and challenging may provide more nuanced insight into the differentiation and role of job demands. 


\subsection{Appraisal of Job Demands}

Whether or not the same job demand is appraised similarly by individuals has seldom been tested [25] but some studies have reported that individual subjective appraisals accounts for the differences regarding whether a job demand is classified as hindering or challenging (e.g., $[9,25])$. Appraisal, in the context of the present study, can be defined as an individual's perception and interpretation of specific job characteristics, and how these job characteristics hold potential for personal growth, gain, and goal achievement (i.e., challenging) or whether they are appraised as constraints that are hindering [26]. Research by Lazarus [27], Lazarus [28], and Bagozzi [29] has contributed to the literature on occupational stress models and appraisals, and they argue that employees make continuous appraisals of their work environments. Based on these appraisals, they form mental representations of which behavior they may apply to cope with these appraisals. Specifically, the Lazarus [27] transactional model of stress and coping (TMSC) suggests that individuals first make primary appraisals, that is, evaluating the significance and importance of a stressful episode, followed by secondary appraisals, which is an evaluation of the available options and resources to handle stressful events [30]. The TMSC suggests that not all stressful episodes will lead to negative stress reactions, which will happen only when the stressors are appraised as exceeding the available resources, and that they will impact well-being negatively. Thus, individuals will appraise stressors or stress episodes differently, and the same stressor may therefore be appraised negatively by one and not by another [28]. Hence, according to the TMSC, appraisals can function as mediators between job demands, well-being, and work outcomes. Research has also revealed that appraisals of job demands may function as moderators of the relationship between job demands and work outcomes $[25,26]$. In line with the person-context interaction theory [31], which states that individual functioning is a result of the interaction between the individual and the environment, Li and Taris [25] as well as Li and Peeters [26] argue that individuals may appraise a stressor (i.e., job demand) as potentially impacting them positively (i.e., challenging), negatively (i.e., hindering), or both. This may, in turn, moderate the relationship between job demands, well-being, and other work outcomes. Although a body of research has revealed a link between job demands, employee strain, and well-being (e.g., [32-34]), this relationship is not fully understood. Job demands may be perceived and experienced in several ways. Investigations of appraisals of job demands are needed to gain knowledge and to validate the hindrance-challenge framework of job demands.

\subsubsection{Nature of Work Belonging to an Occupational Group}

One of the reasons why a given job demand has been classified as hindering or challenging may be due to the nature of work that they are related to. For example, Bakker and Sanz-Vergel [18] found that nurses perceived workload and time pressure as hindering rather than challenging. These hindering demands were experienced as inhibitory and destructive for both personal growth and achieving of work goals. Specifically, high levels of time pressure reduced the quality of patient care. In the same study, the authors describe how a different occupational group, namely journalists, appraised time pressure as a challenging job demand. The nature of many journalists' jobs is to work under a strict time regime. Time pressure may be a job demand that does not hinder journalists from achieving their work goals and rather is a challenge demand they often and successfully overcome, which leads to goal achievement.

Emotional demands at work have been perceived as positive indicators for better performance by some occupational groups. Bakker and Sanz-Vergel [18] reported that emotional demands were experienced as more challenging than hindering among nurses. Nurses experienced both interactions with patients and the need to confront emotional demands as part of their everyday work lives and as part of their job. Conversely, it might be that other occupational groups find emotional demands hindering and not a natural part of their jobs. For instance, it might be that real estate agents can experience emotional 
demands as something outside their core job tasks and as something that will hinder them from achieving their work goals.

Although there are individual differences among employees in occupational groups, there are some characteristics belonging to the job performed by certain occupational groups that may influence the appraisal of job demands. Hence, the role of a given job demand may vary by occupation and may therefore be appraised differently (i.e., as hindering or challenging) not only individually but also based on the nature of the work belonging to that occupational group.

\subsubsection{Positive Trait Emotions}

In addition to the context in which job demands occur (i.e., occupation), individual traits and differences may also impact appraisals of job demands, of which positive trait emotions may play a role. Over the last decade, positive emotions related to work have received increased attention in the literature [35]. For example, evidence has revealed that positive emotions are associated with beneficial job attitudes [36], productivity [37], creativity [38], job crafting [39], organizational citizen behavior, and cooperation with others [40]. However, the majority of the research on the relationship between positive emotions and work outcomes has focused on general positive emotions and thus suggested that all positive emotions are equally related to other work variables [41]. By applying the functional wellbeing approach (FWA, [42,43]), we aim to bring nuance to this topic. According to the FWA, two distinct categories of positive emotions are particularly important for well-being: hedonic feelings, such as pleasure and happiness, and eudaimonic feelings, such as interest and immersion. Hedonic feelings are important because they help sustain homeostatic stability, whereas the major function of eudaimonic feelings is to facilitate change. Hedonic feelings are typically experienced when goals are achieved or needs are fulfilled, i.e., when an equilibrium has been reestablished. Hence, hedonic feelings signal to our minds that our current actions appear to succeed in maintaining our well-being. Relatedly, hedonic feelings also facilitate a kind of mental flexibility, including broadened attention, thus preparing the organism for a change of goals and plans. In contrast, eudaimonic feelings narrow attention to help us stay focused in the process of reaching a difficult goal. Eudaimonic feelings commit us to put in extra effort and to value the striving toward goals, even when the going is rough. Thus, eudaimonic positivity feels different and functions differently than hedonic positivity.

Previous research on emotions in the workplace corroborated the association between hedonic feelings and goal achievement, on the one hand, and that between eudaimonic feelings and the process of overcoming a challenging work task, on the other. For example, Stone and Schwartz [44] found that happiness increased when the workday ended, while building competence had the highest levels during midmorning when demands were dealt with. Similarly, Straume and Vittersø [45] found that hedonic feelings decreased during challenging work tasks, whereas eudaimonic feelings increased. Additionally, research on goal pursuit and goal achievement has revealed similar findings. Thorsteinsen and Vittersø [46] reported in their longitudinal study that eudaimonic well-being initiated and sustained goal pursuit processes, while hedonic well-being was more related to goal achievement.

FWA encompasses both momentary state feelings and more stable and trait-like feelings. According to the FWA, high levels of hedonic feelings predict well-functioning stability, while high levels of eudaimonic feelings predict well-functioning change processes. The orientation to life in hedonic feelings is typically the tendency to evaluate the environment and oneself as good rather than bad, while for eudaimonic feelings, it is the proneness to develop and attain personal growth. Thus, when facing demanding job situations, it is likely that individuals with higher levels of hedonic and eudaimonic feelings will more often evaluate those demands positively and possible to overcome (i.e., good rather than bad) as well as see them as opportunities for utilizing and developing abilities to experience personal growth. This is also in line with Rogala et al. [47], in which 
the authors reported that positive emotions at work did not decrease hindering demands but increased challenging demands.

\subsection{Applying Vignettes}

Vignettes are usually short stories portraying a made-up person and/or a madeup scenario, and vignette studies can be very powerful. For example, Kahneman and Tversky's contributions to economics and psychology was to a large extend due to their observations of the responses people provided to small vignettes [48]. By identifying salient characteristics in a specific context, a vignette approach makes it possible to elicit critical patterns in human thinking and emotions [49,50]. One of the advantages of the methodology for the current study concerns how it makes a standardization of a demanding job situation possible, thus allowing for all participants to respond to the same stimuli [51]. The imaginary nature of vignettes poses a limitation to the design. Hence, a probable association between the imagined and real-life response must be established to generalize the results.

In the present study, we have chosen to investigate appraisals of time pressure and emotional demands for two occupational groups, namely nurses and real estate agents. There are several reasons for choosing these occupational groups. Firstly, we have made an effort to choose occupational groups that differ regarding core work tasks. In line with this, we aimed to investigate job demands (i.e., emotional demands and time pressure) that could have different positive and negative denominations (i.e., hindering or challenging) based on the demands in relation to core tasks within those occupational groups. This includes, for example, that one of the core tasks for nurses is to care for and comfort their patients (i.e., emotional demands), while this is not the case for real estate agents. On the one hand, time pressure is related to core tasks for real estate agents, particularly during bidding rounds. According to Norwegian regulations, when real estate agents receive bids, they are obliged to communicate them in writing to the sellers and other potential bidders, and it is a common practice with 5 to 15 min deadlines, a process that is commonly known to be hectic. On the other hand, time pressure is not recognized as a built-in part of nurses work tasks but may rather be understood as a consequence of understaffing. Finally, both occupations are well-known in Norway and the general population have at least basic knowledge about their core work tasks. Hence, it is reasonable to assume that it is possible for the participants to read vignettes about nurses and real estate agents, and appraise the job situations described.

\subsection{Aims of the Study}

With the present study, we aim to contribute to the job characteristic literature by applying vignettes to investigate the degree to which participants will appraise two job demands (i.e., time pressure and emotionally demanding situations) for two occupational groups (i.e., nurses and real estate agents) as hindering and/or challenging. Additionally, we aim to reveal how the participants' positive trait emotions are related to their appraisals. A vignette study applied on a convenience sample of Norwegian students provides empirical data for the study. We posit the following hypotheses:

Hypothesis 1 (H1). Job demands (i.e., time pressure and emotionally demanding situations) are appraised as hindering and challenging.

Hypothesis 2 (H2). For nurses, time pressure is appraised as more hindering than emotionally demanding situations.

Hypothesis 3 (H3). For nurses, emotionally demanding situations are appraised as more challenging than time pressure.

Hypothesis 4 (H4). For real estate agents, emotionally demanding situations are appraised as more hindering than time pressure. 
Hypothesis $\mathbf{5}$ (H5). For real estate agents, time pressure is appraised as more challenging than emotionally demanding situations.

Hypothesis 6 (H6). Time pressure is appraised as more hindering for nurses than for real estate agents.

Hypothesis 7 (H7). Emotionally demanding situations are appraised as more hindering for real estate agents than for nurses.

Hypothesis $\mathbf{8}$ (H8). Time pressure is appraised as more challenging for real estate agents than for nurses.

Hypothesis 9 (H9). Emotionally demanding situations are appraised as more challenging for nurses than for real estate agents.

Hypothesis 10 (H10). Hedonic and eudaimonic feelings are different concepts and will be accounted for by separate factors.

Hypothesis 11 (H11). Hedonic and eudaimonic feelings are differently related to hindering and challenging appraisals.

\section{Materials and Methods}

\subsection{Design}

To investigate the circumstances under which time pressure and emotional demands are perceived as hindering or challenging, we developed a quasi-experimental study with vignettes. Specifically, we provided two vignettes to the participants, three times each. For each subsequent time the vignette was presented, additional information about the occupation of the person in the vignette was provided. The first time the vignettes were presented, only the employee's name (Hans or Hanna) and demand category (time pressure or emotionally demanding situation) were included. The second and third times the vignettes were presented, we included the occupation of the fictional person in the vignette, who was either a nurse or real estate agent.

The first vignette described a job situation with high-time pressure: "Hanna/Hans has been at work for a few hours. She or he has not been able to take a break yet. It is not certain that she or he will have time to sit down during the rest of the workday. There are many job tasks to be done, and the tempo is high. It is often like this at Hanna's/Hans' job. She or he must often choose which job tasks should be prioritized and which job tasks must wait. A hectic day at work often means that Hanna/Hans are not able to perform all the tasks of the day before she or he goes home, and it is not unusual that she or he must work extra hours and at unfavorable times of the day. To what degree do you think Hanna/Hans is experiencing her or his job as ... " Then, six appraisal items were presented as detailed in the Section 2.3 below.

The second vignette described an emotionally demanding job situation: "Hans/Hanna has been at work a few hours when he or she gets into a situation with a woman who is having a very hard time. The woman cries a lot. Hans/Hanna feels like the woman is overwhelmed with emotions and that she is seeking help from him or her to handle the situation she is currently in. It is hard for Hans/Hanna to understand what the woman is trying to tell him or her; she cries so much that it is hard to have a conversation. The woman takes a long time to be able to find the words to describe what she wants and appears somewhat chaotic when meeting Hans/Hanna. To what degree do you think Hans/Hanna is experiencing his or her job as ... ". Again, the six appraisal items were presented (see below).

The participants were randomly selected into one of two conditions, in which the persons' gender and profession in the vignettes varied. See Figure 1 for the flow diagram. 


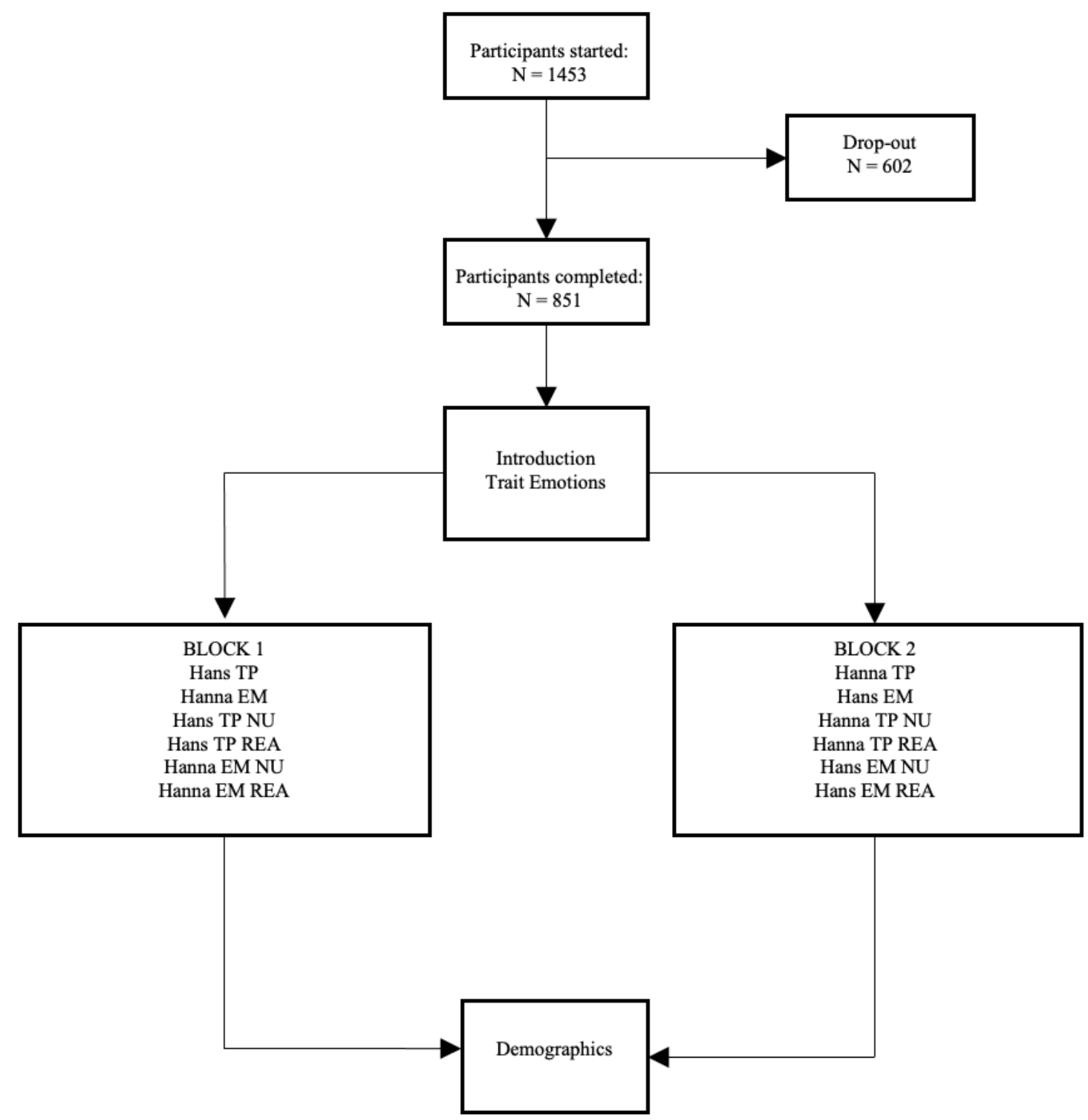

Figure 1. Flow diagram. Abbreviations: $\mathrm{TP}=$ time pressure; $\mathrm{EM}=$ emotionally demanding situation; $\mathrm{NU}=\mathrm{nurse}$; and $\mathrm{REA}=$ real estate agent.

\subsection{Participants}

Of 1453 students, 851 in the age range from 16 to $56(M=25.22, S D=5.25)$ completed the survey and were included in the analyses, of which $77.6 \%$ were women $(N=664)$ and $21.8 \%$ were men $(N=187)$. The students came from a broad variety of study fields: $191(22.3 \%)$ in psychology, $221(25.8 \%)$ in nursing, $30(3.5 \%)$ in real estate, $84(9.8 \%)$ in economics, 111 (13\%) in law, and $213(24.9 \%)$ in "other study fields". The students were invited to participate in an electronic survey through various social media platforms and by e-mail.

\subsection{Measures}

Data were analyzed using IBM SPSS 25 (IBM, Armonk, NY, USA) and Mplus version 8 [52]. Age and gender were controlled for.

\subsubsection{Appraisal of Job Demands}

To measure the participants' appraisal of job demands as hindering or challenging, we applied six items previously used by Bakker and Sanz-Vergel [18]. The adjectives 
were introduced after the vignettes with the text: "To what extent do you believe that Hans/Hanna experienced the situations as ....". Responses were given on endpointlabeled scales, ranging from 1 (to a small degree) to 5 (to a large degree). A principal axis exploratory factor analysis with promax rotation suggested that two factors may account for the correlations between the demand variables. Two eigenvalues were higher than 1 and a parallel analysis [53] also supported the choice of a two-factor solution. Since the correlation between the two factors was trivial $(\mathrm{r}=-0.05)$, we reran the final model with varimax rotation. Different from Bakker and Sanz-Vergel [18], who conceptualized hindrance demands as consisting of the three items of "hindering", "stressful", and "demanding", our analysis also revealed that the item "challenge" belonged to this factor. Furthermore, our results revealed that the second factor consisted of the items "interesting" and "motivating." We believe this result is due to the Norwegian language, in which the term "challenge" has a more negative connotation than in English and even more so when reading about demanding situations (i.e., vignette stories). Hence, "challenge" is therefore associated with negative appraisals, while "interesting" and "motivating" represent positive appraisals. Accordingly, we believe that our factor structure does correspond to the hindrance-challenge framework reported in previous studies. Nevertheless, to make visible that our factor structure is different, we chose to apply the terms "hindrance-like" for hindering (i.e., negative) appraisals and "challenge-like" for challenging (i.e., positive) appraisals when reporting our findings. Two mean-score demand variables were computed with Cronbach's $\alpha=0.82$ for the hindrance-like subscale and $\alpha=0.83$ for the challenge-like subscale.

\subsubsection{Emotions}

Trait-level emotions were measured with the Basic Emotions Trait Test (BETT, [54]). A short version of the scale is comprised of nine items reflecting five basic emotions (happiness, interest, fear, anger, and sadness). The two positive emotions represent hedonic (i.e., happiness) and eudaimonic emotions (i.e., interest), respectively, whereas the three negative emotions may be summarized as a single negative composite score [43]. The participants were asked to report the overall frequency of the five basic emotions in their lives overall. The introduction reads "In general, how often do you feel ... " followed by nine adjectives or adjective phrases. For example, "happy" or "scared" (adjectives) or "completely absorbed in what I am doing" (adjective phrase). The response options ranged from $0=$ never to $6=$ all the time. To check the three-dimensional structure of the test, we ran a principal axis exploratory factor analysis with promax rotation. Three eigenvalues were higher than 1 and a parallel analysis [53] also supported the choice of a three-factor solution. Negative emotions were not used in the present study; hence, two mean-score emotion variables were computed for subsequent analyses with Cronbach's alphas $\alpha=0.86$ for the hedonic emotions subscale and $\alpha=0.79$ for the eudaimonic emotions subscale. We take this result as evidence for $\mathrm{H} 10$.

\section{Results}

Table 1 presents the means, standard deviations, skewness, and varimax-rotated factor loadings for the demand items.

The participants' gender $(\operatorname{man}=0$, woman $=1)$ was significantly related to hindrancelike appraisals $(B=0.18, p<0.001)$, whereas age was not $(p=0.485)$. Similarly, the participants' gender $(B=0.20, p<0.001)$, but not age $(p=0.720)$, was related to challengelike appraisals. Hence, age was excluded from subsequent analysis. A multilevel (mixed model) regression analysis with grand-mean-centered variables showed that the intraclass correlations (ICC) were 0.29 for hindrance-like demands and ICC $=0.19$ for challenge-like demands. Overall, no mean differences were found between time pressure and emotional demands, neither for hindrance-like $(p=0.401)$ nor challenge-like $(p=0.061)$ demands. Looking more closely at the different vignettes, however, provides a more differentiated picture. A factorial repeated measure (GLM) was conducted with gender as the 
between-participant covariate. Separate models were run for hindrance-like demands and challenge-like demands, and the results are summarized in Figures 2 and 3, respectively, showing means and standard errors for the six vignettes for males and females separately. For hindrance-like demands, the Huynh-Feldt sphericity was $\varepsilon=0.81$. The main effect was significant, $F(4.02,3400)=68.64, p<0.001$, as was the interaction with gender, $F(4.02,3400)=4.79, p=0.001$. Although the overall interaction test was significant, the $95 \% \mathrm{CI}$ for males and females did not overlap in the no-job emotional and the two nurse vignettes. For challenge-like demands, the Huynh-Feldt sphericity was $\varepsilon=0.92$. The main effect was significant, $F(4.62,3891)=186, p<0.001$, but the interaction with gender was not, $F(4.02,3400)=1.81, p=0.113$. Although the overall interaction test was non-significant, the $95 \% \mathrm{CI}$ for males and females did not overlap in the no-job emotion, nurse time pressure, and real estate time pressure vignettes, indicating a post-hoc interaction effect for these three conditions.

Table 1. Means, standard deviations, skewness, varimax-rotated factor loadings, eigenvalues, and explained covariance for the demands items.

\begin{tabular}{lccccc}
\hline & Mean & SD & Sk & $\boldsymbol{F 1}$ & $\boldsymbol{F 2}$ \\
\hline Demanding & 4.04 & 0.89 & -0.84 & $\mathbf{0 . 8 8}$ & 0.00 \\
Difficult & 3.64 & 0.99 & -0.34 & $\mathbf{0 . 8 3}$ & -0.17 \\
Challenging & 4.00 & 0.87 & -0.76 & $\mathbf{0 . 8 0}$ & 0.19 \\
Stressful & 3.88 & 1.08 & -0.77 & $\mathbf{0 . 7 4}$ & -0.10 \\
Interesting & 3.14 & 1.16 & -0.20 & 0.02 & $\mathbf{0 . 9 2}$ \\
Motivating & 2.90 & 1.19 & 0.02 & -0.08 & $\mathbf{0 . 9 2}$ \\
Eigenvalues & & & & 2.67 & 1.75 \\
Explained covariance (\%) & & & & 44.54 & 29.22 \\
\hline
\end{tabular}

Note: $N=5081$. Factor loadings $>0.30$ in bold. Abbreviations: $F 1=$ hindrance-like and $F 2=$ challenge-like.

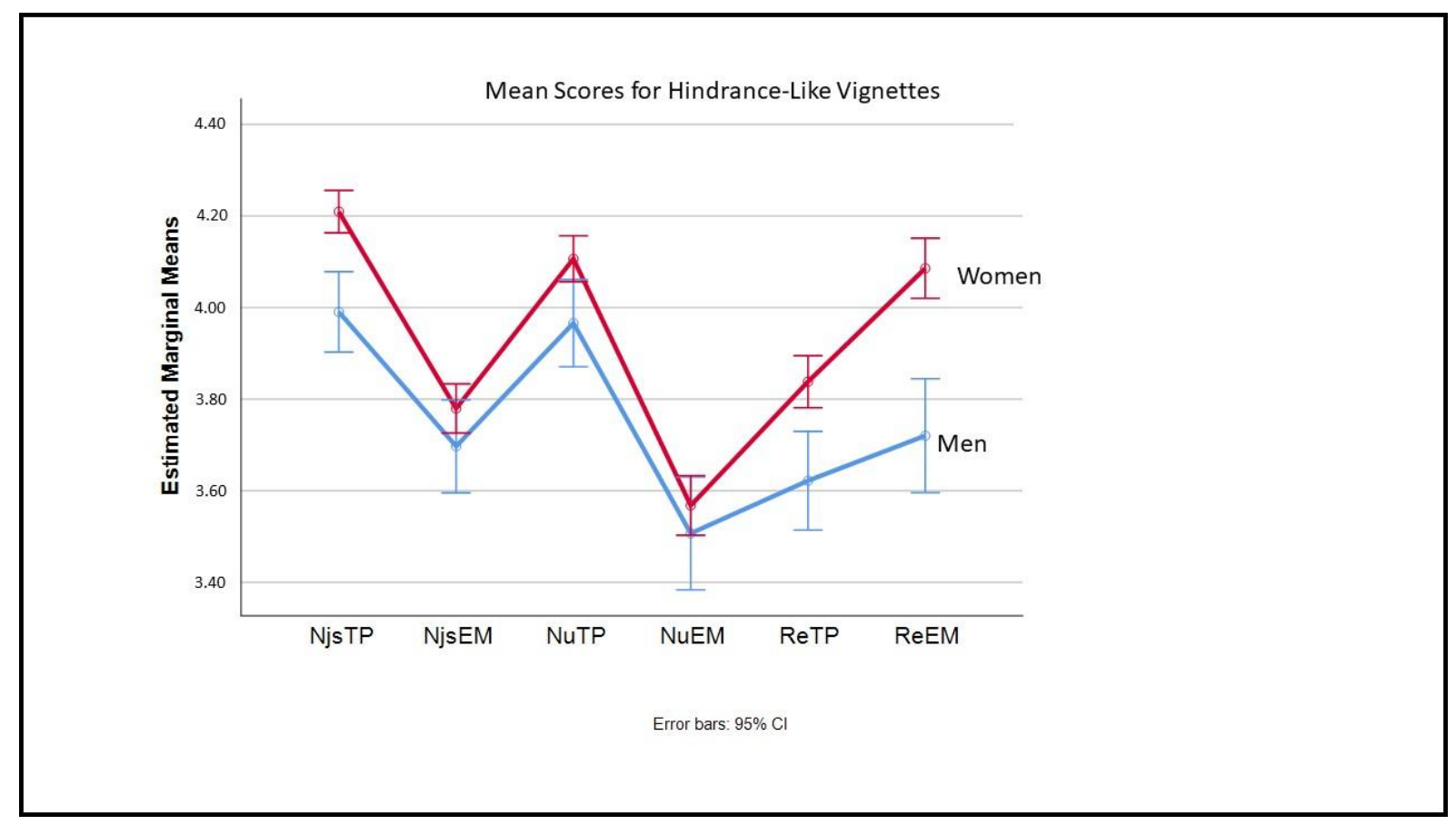

Figure 2. Means and error bars for hindrance-like appraisals across six vignettes. Abbreviations: NjsTP = no jobs specified in time pressure condition; $\mathrm{NjsEM}=$ no jobs specified in the emotionally demanding condition; $\mathrm{NuTP}=$ nurse in the time pressure condition; $\mathrm{NuEM}=$ nurse in the emotional condition; ReTP = real estate agent in the time pressure condition; and ReEM = real estate agent in the emotionally demanding condition. 


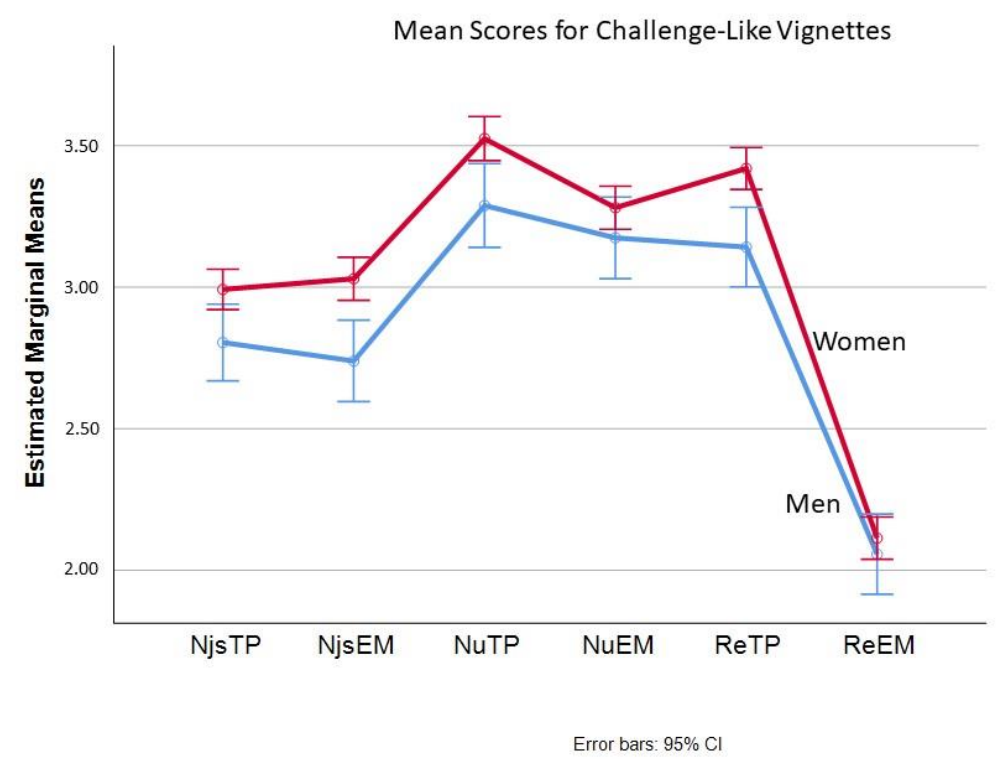

Figure 3. Means and error bars for challenge-like appraisals across six vignettes. Abbreviations: NjsTP = no jobs specified in time pressure condition; $\mathrm{NjsEM}=$ no jobs specified in the emotionally demanding condition; $\mathrm{NuTP}=$ nurse in the time pressure condition; $\mathrm{NuEM}=$ nurse in the emotional condition; $\mathrm{ReTP}=$ real estate agent in the time pressure condition; and ReEM = real estate agent in the emotionally demanding condition.

To further test the hypotheses, we conducted post-hoc paired sample $t$-tests. As hypothesized in H1, time pressure and emotional demands were appraised as hindrancelike and challenge-like. Specifically, the overall mean hindrance-like score, $M=3.89$, $S D=0.50$, was higher than that of the challenge-like score, $M=3.02, S D=0.62$. A paired sample $t$-test showed that this difference was significant, $t(850)=34.61, p<0.001$ (twotailed). We further divided the two variables into time pressure hindrance-like and time pressure challenge-like, and observed that the former $(M=4.01, S D=0.54)$ was significantly higher than the latter $(M=3.2, S D=0.73), t(850)=24.6, p<0.001$ (two-tailed). For the emotional demands, the hindrance-like scores $(M=3.77, S D=0.59)$ were also higher than the challenge-like scores, $(M=2.77, S D=0.75), t(850)=32.61, p<0.001$.

The hindrance-like scores for nurses during time pressure situations $(M=4.07, S D=0.66)$ were higher than those during emotionally demanding situations $(M=3.56, S D=0.85)$ and a paired-sample $t$-test showed that the difference was significant, $t(846)=18.75, p<0.001$ (twotailed), supporting $\mathrm{H} 2$. The challenge-like scores for nurses during emotionally demanding situations $(M=3.25, S D=1.00)$ were lower than those during time pressure situations $(M=3.47, S D=1.03)$ and a paired-sample $t$-test showed that the difference was significant, $t(846)=5.98, p<0.001$ (two-tailed). H3 was not supported.

In line with $\mathrm{H} 4$, the hindrance-like scores for real estate agents during emotionally demanding situations $(M=4.01, S D=0.87)$ were higher than those during time pressure situations $(M=3.80, S D=0.76)$ and a paired-sample $t$-test showed that the difference was significant, $t(846)=-7.02, p<0.001$ (two-tailed). The challenge-like scores for real estate agents during time pressure situations $(M=3.36, S D=0.98)$ were higher than those during emotionally demanding situations $(M=2.01, S D=0.98)$ and a paired-sample $t$-test showed that the difference was significant, $t(845)=30.28, p<0.001$ (two-tailed). H5 was supported.

The hindrance-like scores for time pressure were higher for nurses $(M=4.07, S D=0.66)$ than for real estate agents $(M=3.79, S D=0.75)$ and a paired-sample $t$-test showed that the difference was significant, $t(848)=10.66, p=0.001$ (two-tailed). H6 was supported. The hindrance-like scores for emotionally demanding situations were lower for nurses 
$(M=3.56, S D=0.85)$ than for real estate agents $(M=4.01, S D=0.87)$ and a paired-sample $t$-test showed that the difference was significant, $t(846)=-11.72, p<0.001$ (two-tailed), confirming H7.

The challenge-like scores for time pressure were higher for nurses $(M=3.47, S D=1.03)$ than for real estate agents $(M=3.35, S D=0.98)$ and a paired-sample $t$-test showed that the difference was significant, $t(848)=2.76, p=0.006$ (two-tailed). H8 was not supported. The challenge-like scores for emotionally demanding situations were also higher for nurses $(M=3.25, S D=1.00)$ than for real estate agents $(M=2.10, S D=0.98)$ and a paired-sample $t$-test showed that the difference was significant, $t(845)=28.53, p<0.001$ (two-tailed), confirming $\mathrm{H} 9$.

The only effect of gender of the employee in the vignette was seen for hindrancelike scores among nurses: Hanna was assigned higher scores for the emotional vignette, $(M=3.64, S D=0.81)$ than Hans $(M=3.46, S D=0.89)$ and a paired-sample $t$-test showed that the difference was significant, $t(846)=3.04, p=0.002$ (two-tailed).

In line with $\mathrm{H} 10$, our results revealed that hedonic and eudaimonic feelings are different concepts accounted for by different factors. Table 2 presents the means, standard deviations, skewness, pattern matrix, and factor correlations for the trait-level emotions.

Table 2. Means, standard deviations, skewness, pattern matrix, eigenvalues, explained covariance, and factor correlations for the Basic Emotions Trait Test (BETT). Note: $N=828$; promax rotation; factor loadings $>0.30$ in bold; $F 1=$ hedonic emotions; $F 2$ = eudaimonic emotions; and F3 = negative emotions.

\begin{tabular}{lcccccc}
\hline & Mean & SD & Sk & $\boldsymbol{F 1}$ & $\boldsymbol{F 2}$ & $\boldsymbol{F 3}$ \\
\hline Pleased & 4.76 & 1.09 & -0.59 & $\mathbf{0 . 9 4}$ & -0.02 & 0.09 \\
Satisfied & 5.18 & 1.01 & -0.98 & $\mathbf{0 . 7 9}$ & 0.03 & -0.05 \\
Happy & 4.91 & 1.20 & -0.83 & $\mathbf{0 . 7 5}$ & -0.02 & -0.02 \\
Immersed & 4.35 & 1.30 & -0.19 & -0.05 & $\mathbf{0 . 8 3}$ & 0.03 \\
Engaged & 4.88 & 1.23 & -0.43 & 0.10 & $\mathbf{0 . 7 7}$ & -0.02 \\
Absorbed & 4.16 & 1.34 & -0.28 & -0.05 & $\mathbf{0 . 6 8}$ & 0.00 \\
Sad & 3.20 & 1.27 & 0.48 & -0.09 & -0.04 & $\mathbf{0 . 7 6}$ \\
Scared & 2.54 & 1.25 & 1.01 & 0.02 & 0.06 & $\mathbf{0 . 6 2}$ \\
Angry & 2.97 & 1.19 & 0.63 & 0.08 & 0.00 & $\mathbf{0 . 5 1}$ \\
Eigenvalues & & & & 3.32 & 1.87 & 1.15 \\
Explained covariance (\%) & & & & 32.80 & 15.99 & 7.37 \\
Factor correlations F1 & & & & 1.00 & 0.33 & -0.55 \\
Factor correlations F2 & & & & & 1.00 & -0.15 \\
Factor correlations F3 & & & & & & \\
\hline Factor loadings > 0.30 in bold & & & & & & 1.00 \\
\hline
\end{tabular}

Factor loadings $>0.30$ in bold.

Finally, we fitted a multilevel path model to the data (Figure 4). The model included hindrance-like and challenge-like appraisals as dependent variables, alongside hedonic feelings, eudaimonic feelings, and gender as the independent variables. The model depicted in Figure 4 was saturated, with zero degrees of freedom (hence, no goodness-of-fit estimates were available). Gender predicted both hindrance-like appraisals $(\beta=0.18$, $p<0.001)$ and challenge-like appraisals $(\beta=0.18, p<0.001)$. Hindrance-like appraisals were not significantly associated with emotions ( $p s>0.239)$, whereas challenge-like appraisals were predicted by both hedonic feelings $(\beta=0.12, p=0.008)$ and eudaimonic feelings $(\beta=0.12, p=0.014)$. This result was not consistent with H11. 


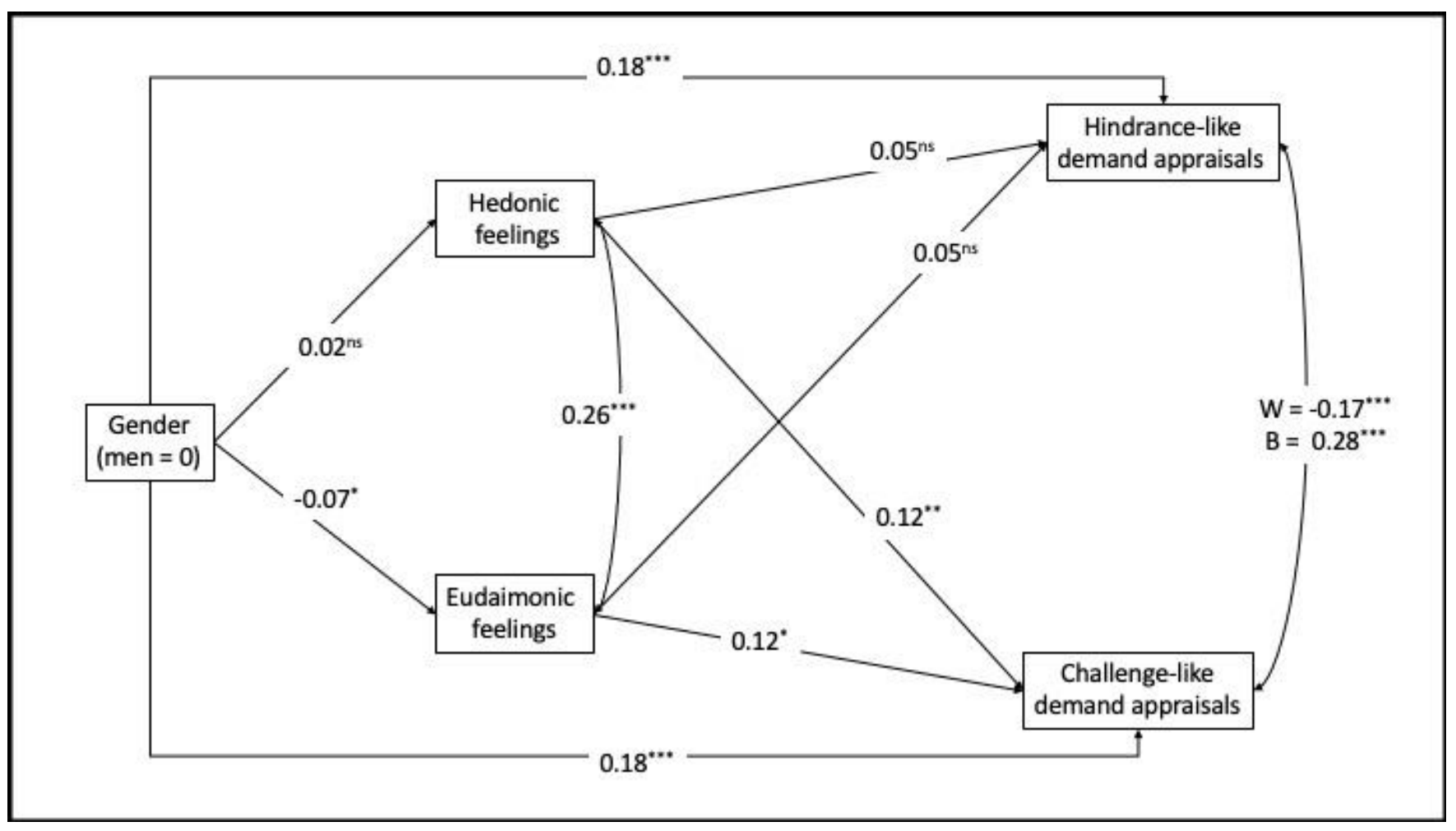

Figure 4. Between-participants standardized regression paths. The correlation between hindrance-like and challenge-like between-participants $(B)$ and within participants $(\mathrm{W}) .^{*}=p<0.05 ;{ }^{* *}=p<0.01 ;{ }^{* * *}=p=0.001$; ns $=$ non-significant.

\section{Discussion}

We aimed to contribute to the job characteristics literature by using a vignette study. Norwegian students with no specified work experience imagined how time pressure and emotionally demanding situations might have been appraised as hindrances and/or challenges for nurses and real estate agents. We also analyzed the participants' own trait emotions and how these were related to the vignette appraisals.

Typically, when differentiating job demands, the scientific literature has presented this in a hindrance-challenge framework (e.g., $[6,16,21,55]$ ). In previous research, the items that have been used to measure challenge and hindrance demands were most often decided a priori; that is, researchers decided which items (i.e., adjectives) measure hindrance demands and challenge demands before the measures are done. In our study, we wanted to explore to what degree the appraisals could have both a positive and negative denomination at the same time. Thus, we chose to apply the six adjectives previously applied to measure hindrance and challenge demands [18], but also applied a data-driven approach that grouped the items in accordance with the result from the factor analysis. Our results revealed a similar division between "good" and "bad" job demands, as did the Bakker and Sanz-Vergel [18] study, but differed from those of previous studies in that the item "challenge" was loaded with items belonging to the previously reported subscale of hindrance demands (i.e., "hindering", "stressful", and "difficult") and not with the more positive appraisal items "motivating" and "interesting". Several reasons may account for these results. First, it might be due to language. Although the Norwegian word for challenging (i.e., utfordring) holds both positive and negative connotations, depending on the context, the term has more negative connotations than the English term. It is not unreasonable to assume that this difference in meaning contributed to the different factor structures. Second, when applying vignettes, the reader might underestimate the engagement of the person in the vignette in demanding situations. When a person is engaged, the term challenge is often positively charged. When a person is disengaged or stressed, the term challenge is often negatively charged. In connection with our previous 
argument regarding the Norwegian term for challenge, when evaluating the fictional persons' experience (i.e., how do you think Hanna/Hans experienced this situation), it might be that underestimation of engagement led to challenge having mostly negative connotations in our study. Taken together, we believe that our factor structure does correspond with the previously reported labels of hindrance and challenge demands. Nonetheless, since our results did have a different factor structure than previous studies, instead of using the labels hindrance and challenge, we applied the labels hindrance-like and challenge-like, respectively. However, when we used the terms hindrance-like and challenge-like, our intention was merely to make visible that our results revealed that one item (i.e., challenge) loaded differently from previous studies. Hence, the new labels (i.e., hindrance-like and challenge-like) are, in our opinion, representing the same meaning as the previously used labels (i.e., hindrance and challenge).

In line with H1, when no job was specified, both job demands (i.e., time pressure and emotionally demanding situations) were appraised as hindrance-like and challenge-like to different degrees, specifically more hindrance-like than challenge-like. This is in line with the literature reporting that all job demands require sustained effort and even if some job demands have motivational potential, all job demands have costs [56]. This is also in line with the literature reporting that the same job demands can be appraised as hindering and challenging at the same time $[18,26]$. Thus, it seems that imagined and real-life job demands share some basic characteristics, although the results from the two approaches are not identical.

We argued that the nature of work belonging to an occupational group could impact the degree to which job demands were appraised as hindering or challenging and that this was related to whether the job demand typically hindered the occupational group from achieving their work goals. Thus, we hypothesized that time pressure would be appraised as more hindering for nurses than emotional demands (H2). Specifically, and as expected, time pressure for nurses was appraised as more hindrance-like than emotional demands, in line with the literature that revealed how time pressure prevents nurses from achieving their work goals and attending to patient care [57]. In addition, emotional demands in which a nurse is offering care and comfort are viewed as one of the core work characteristics for nurses and therefore as less preventive of goal achievement, although these situations require effort. Moreover, among the appraisals of hindrance-like demands, the vignette with nurses facing emotional demands received the lowest score. We also hypothesized that emotional demands would be appraised as more challenging than time pressure (H3). This hypothesis was not supported, as we unexpectedly found that time pressure was appraised as more challenge-like than emotional demands. One of the reasons for this finding may be that when the participants, who were not nurses, read the vignettes, they interpreted emotional demands as a very clear part of the nurse's daily job tasks. Thus, their appraisal may reflect that they believe the nurse will solve these situations (i.e., they are to a little degree hindering) and that emotional demands are such an integrated part of their daily jobs that they were not appraised as challenging, as expected.

Furthermore and in line with $\mathrm{H} 4$, we found that for real estate agents, the participants appraised emotional demands to be more hindrance-like than time pressure. Moreover and in line with $\mathrm{H} 5$, time pressure was appraised as more challenge-like than emotional demands. This may be explained by the nature of work belonging to this occupational group, in which emotional demands may not be considered a core work experience, while time pressure is part of real estate agents' daily activities (e.g., bidding rounds). Additionally, emotional demands were appraised to be less challenge-like for real estate agents than the other six job situations described in the vignettes. These findings are also in line with the literature that describes how short-term time pressure (e.g., during a workday with deadlines), which is something real estate agents regularly face during their workday, can be motivational [58].

When comparing appraisals of the job demands for the two occupational groups, we found, as hypothesized in H6, that time pressure was appraised as more hindrance-like 
for nurses than for real estate agents and, in line with $\mathrm{H7}$, that emotional demands were appraised more hindrance-like for real estate agents than for nurses. These results align with the literature which revealed that job demands that are typically part of the nature of work in an occupation are appraised as less hindering than job demands that are faced less frequently as part of the work (e.g., [18,55]). Although nurses are struggling with time pressure on a frequent level, it is not considered a part of their work in a way that helps them achieve their work goals. Thus, time pressure is appraised as hindering them to a greater degree than time pressure is hindering real estate agents, who frequently encounter time pressure as a part of their work tasks. Conversely, real estate agents are not as experienced in facing emotional demands as part of their job; therefore, real estate agents may appraise emotional demands as more hindering compared to nurses who are expected to handle emotional demands as an integrated part of their work.

We hypothesized that time pressure would be appraised as more challenging for real estate agents than for nurses (H8). However, and unexpectedly, time pressure was appraised as more challenge-like for nurses than for real estate agents. This result may be related to the finding that time pressure unexpectedly was appraised as more challenge-like than was emotional demands for nurses (H3). Thus, overall, time pressure for nurses was appraised as more challenge-like than we expected, both when we measured this only for nurses (i.e., comparing challenge-like appraisals between time pressure and emotional demands for nurses) and between occupational groups (i.e., comparing challenge-like appraisals of time pressure between nurses and real estate agents). These findings may also reflect what the participants, who are not nurses, believe about nurses' jobs. For example, in the Norwegian media, nurses are often portrayed as working under intense time pressure. This portrayal of nurses working under constant time pressure may lead others (i.e., participants) to interpret time pressure as a core job characteristic that nurses must overcome, different from nurses themselves who report time pressure as preventing them from doing their job in the way they want to. Hence, the appraisals of time pressure for nurses may therefore be appraised as more challenge-like than we expected. Additionally, emotional demands were, as expected and in line with $\mathrm{H} 9$, appraised as more challenge-like for nurses than for real estate agents. This result is in line with how we expect nurses to handle emotionally demanding situations as a part of their daily work, while the same is not expected for real estate agents. Additionally, it is in line with the literature reporting on how some demands do have motivational potential, although they require sustained effort, e.g., [8].

Altogether, our findings from H1-H9 revealed that the same job demands can be appraised as hindrance-like and challenge-like to different degrees within an occupational group and that when two occupational groups are compared, the same pattern follows. Thus, categorizing job demands a priori as having either a negative or positive impact on employee well-being does not seem to bring enough nuance to the understanding of job demands. Rather, it seems that the degree to which job demands are appraised as hindrance-like or challenge-like is not only due to the job demand itself but is also connected to the context within which the job demand occurs (i.e., occupation). Even though $\mathrm{H} 3$ and $\mathrm{H} 8$ were not supported, the overall results were meaningful and supportive of our suggestion that job demands are better understood when approached more nuanced, as opposed to categorizing them a priori. Moreover, our findings support our proposal that each job demand should be measured in such a way that the degree of positive (i.e., challenge-like) and negative (i.e., hindrance-like) appraisals may be captured when they occur simultaneously. Additionally, our results support the notion that some job demands (i.e., challenge-like) may also play a role in the motivational process of the JD-R model and not only in the health-impairment process.

We wanted to investigate how the participants' positive trait emotions were related to their appraisals of job demands. Specifically, we hypothesized that hedonic and eudaimonic feelings would be differently related to hindrance and challenging demands (H11). Our Hypoth was, however, not confirmed. This result was surprising given the large number 
of previous studies showing how hedonic feelings are unrelated or even negatively related to challenging tasks, whereas eudaimonic feelings are positively associated with such tasks (see Vittersø, 2016, for an overview). Again, a possible reason might be that our data derives from participants imagining how other people might be feeling in challenging situations and not from real feelings in such situations. Some studies indicate that people underestimate the positivity evoked in the process of being immersed in overcoming a challenging task (e.g., [59]) and we speculate that an underestimation of eudaimonic feelings in challenge-like demand appraisals may account for the current result.

Finally, some gender effects were found. We observed gender differences among the participants in which women reported higher scores on all appraisals of job demands, both in the hindrance-like and challenge-like conditions. This finding may be explained by a relatively consistent finding in the literature, namely that women are expected to display stronger emotional expressivity than men. These differences are observed both for negative and positive emotions [60]. The underlying reason for these differences may stem from role development by which women are socialized to be emotionally expressive and men are socialized to express fewer emotions [61]. According to poststructuralist feminist theories, different emotional roles for women and men have also been found in workplaces integrated as part of organizational norms and practices [62]. Thus, when responding to the questionnaires used in our study, women may tend to score higher than men. Nonetheless, although women reported higher scores than men on all 12 appraisal conditions, the responses followed the same patterns, as depicted in Figures 2 and 3.

We also found one effect of the gender of the employee in the vignette, namely that when reading about nurses, the emotional demands were rated as more hindering for Hanna than for Hans. This one-employee gender effect may be explained by the shifting standards model [63], which suggests that when we make judgments about members of a social category (e.g., men) based on stereotype-relevant dimensions, these judgments are based on comparing standards for the within-group (e.g., judging a man relative to a male standard). Society still views nursing as a gender-specific occupation and the public perspective is that nursing consists of female-associated qualities, such as compassion and caring [64]. Additionally, women are overrepresented as nurses; for example, in Norway, only $11.4 \%$ of nurses were men in 2020 [65]. Thus, when the participants evaluated Hans' experience in the emotionally demanding situation, they may have attributed femaleassociated traits of nursing (i.e., care and compassion) to him and with that, according to the shifting standards model, compared him to other men, which again led to lower hindrance-like scores for Hans in the emotionally demanding situations. These findings were not obtained when the participants appraised the job demands faced by the real estate agents. One reason for this may be that this is a profession with more gender equality, as almost $40 \%$ of this profession in 2020 in Norway were women [66]. Moreover, for the other vignettes, there were no effects of the gender of the employee.

\subsection{Limitations and Future Research}

There are some limitations to this study that need to be acknowledged. First, when applying vignettes, it is possible that the assessments of the hypothetical job demands were less externally valid than if they were obtained by actual nurses and real estate agents. Moreover, the external validity could also be stronger if the situations were experiences in the field and not in fictional stories with fictional characters. Furthermore, our participants were relatively young and their job experiences were unknown. Nevertheless, previous studies have found that hypothetical situations can evoke similar reactions to those obtained in the field [67], even if it cannot be guaranteed that the same reactions and appraisals would have found place in real-life settings [49]. Another limitation that must be recognized is that we do not know if the participants based their appraisal on occupational stereotypes and how this may have influenced the results. Moreover, all participants were students and it is unknown whether they had previous work experiences. Thus, our findings cannot be generalized to other populations. Clearly, a replication study 
with nurses and real-estate agents reporting from their actual work experiences would strengthen the generalizability and external validity of the presented results.

Although our factor analyses resulted in similar differentiations of job demands as in previous studies, that is, positive and negative, our study differed in that the items "hindrance" and "challenge" belonged to the same factor (i.e., hindrance-like demands). Future studies should attempt to validate the differentiation of challenge-like and hindrance-like demands, particularly in Norway but also in other areas of the world.

Finally, we focused only on job demands (i.e., time pressure and emotionally demanding situations) and on how knowledge of an occupational group and individual trait emotions affected the appraisals of these demands. We did not investigate how these demands were related to, for example, work engagement and burnout, or other outcome variables. To validate that challenge-like job demands have motivational potential, it would be fruitful to design studies that also measure these relationships.

\subsection{Conclusions}

Despite the limitations, our study extends the understanding of the challenge-hindrance framework for job demands. Using a vignette approach, the present study showed that hindrance and challenge are separate, though related, dimensions of the concept of job demands. We also found that the same job characteristics were appraised differently depending on the occupational group they belonged to. In addition, our study revealed that positive trait emotions predicted challenge appraisals but not hindrance appraisals. Furthermore, our results revealed that job demands can be appraised as challenges and hindrances at the same time. This indicates that it is too simplistic to categorize a job demand as hindering or challenging a priori. Knowledge about the positive and negative potential of job demands is important when researching the nature and consequences of job demands, and calls for a nuanced approach in future job characteristics research.

Our findings also have implications for the development of sustainable work environments. That is, knowledge concerning to which degree demands have a motivational potential (i.e., challenge) and/or are distressing (i.e., hindrance) is important for facilitating and strengthening employee well-being.

Author Contributions: Conceptualization, B.L.-E. and J.V.; methodology, B.L.-E. and J.V.; software, J.V. and B.L.-E.; validation, B.L.-E. and J.V.; formal analysis, J.V.; investigation, B.L.-E.; resources, B.L.-E. and J.V.; data curation B.L.-E. and J.V.; writing-original draft preparation, B.L.-E. and J.V.; writing-review and editing B.L.-E. and J.V.; visualization, B.L.-E. and J.V.; project administration, B.L.-E. and J.V.; funding acquisition, J.V. and B.L.-E. All authors have read and agreed to the published version of the manuscript.

Funding: This work was supported by the Northern Norway Regional Health Authority (grand number HST1186-14). The publication charges for this article were funded by a grant from the publication fund of UiT The Arctic University of Norway.

Institutional Review Board Statement: This study followed the guidelines of the Declaration of Helsinki and further approval by an ethics committee was not required as per applicable institutional or national guidelines and regulations.

Informed Consent Statement: Informed consent was obtained from all subjects involved in the study.

Data Availability Statement: The data are protected and not openly available.

Acknowledgments: We would like to thank Rikke Eliesen for coordinating the data collection.

Conflicts of Interest: The authors declare no conflict of interest.

\section{References}

1. Bakker, A.B.; Demerouti, E. Job Demands-Resources Theorem. In Wellbeing: A Complete Reference Guide; Cooper, C., Chen, P., Eds.; Wiley-Blackwell: Chichester, UK, 2014; pp. 1-28.

2. Bakker, A.B.; Demerouti, E.E. Job demands-resources theory: Taking stock and looking forward. J. Occup. Heal. Psychol. 2017, 22, 273-285. [CrossRef] 
3. Bakker, A.B.; Demerouti, E.; Sanz-Vergel, A.I. Burnout and Work Engagement: The JD-R Approach. Annu. Rev. Organ. Psychol. Organ. Behav. 2014, 1, 389-411. [CrossRef]

4. Molino, M.; Bakker, A.B.; Ghislieri, C. The role of workaholism in the job demands-resources model. Anxiety Stress Coping 2015 29, 400-414. [CrossRef]

5. Langseth-Eide, B. It's Been a Hard Day's Night and I've Been Working Like a Dog: Workaholism and Work Engagement in the JD-R Model. Front. Psychol. 2019, 10. [CrossRef]

6. LePine, J.A.; Podsakoff, N.P.; LePine, M.A. A meta-analytic test of the challenge stressor-hindrance stressor framework: An explanation for inconsistent relationships among stressors and performance. Acad. Manag. J. 2005, 48, 764-775. [CrossRef]

7. Luchman, J.N.; González-Morales, M.G. Demands, control, and support: A meta-analytic review of work characteristics interrelationships. J. Occup. Health Psychol. 2013, 18, 37. [CrossRef] [PubMed]

8. Broeck, A.V.D.; De Cuyper, N.; De Witte, H.; Vansteenkiste, M. Not all job demands are equal: Differentiating job hindrances and job challenges in the Job Demands-Resources model. Eur. J. Work. Organ. Psychol. 2010, 19, 735-759. [CrossRef]

9. Searle, B.J.; Auton, J.C. The merits of measuring challenge and hindrance appraisals. Anxiety Stress Coping 2015, 28, 121-143. [CrossRef] [PubMed]

10. Webster, J.R.; Beehr, T.A.; Love, K. Extending the challenge-hindrance model of occupational stress: The role of appraisal. J. Vocat. Behav. 2011, 79, 505-516. [CrossRef]

11. Cavanaugh, M.A.; Boswell, W.R.; Roehling, M.V.; Boudreau, J.W. An empirical examination of self-reported work stress among U.S. managers. J. Appl. Psychol. 2000, 85, 65-74. [CrossRef]

12. Schaufeli, W.B.; Bakker, A.B. Job demands, job resources, and their relationship with burnout and engagement: A multi-sample study. J. Organ. Behav. 2004, 25, 293-315. [CrossRef]

13. Lin, M.; Ling, Q. Is role stress always harmful? Differentiating role overload and role ambiguity in the challenge-hindrance stressors framework. Tour. Manag. 2018, 68, 355-366. [CrossRef]

14. Kawai, N.; Mohr, A. The Contingent Effects of Role Ambiguity and Role Novelty on Expatriates' Work-related Outcomes. Br. J. Manag. 2014, 26, 163-181. [CrossRef]

15. Semmer, N.K.; Jacobshagen, N.; Meier, L.L.; Elfering, A.; Beehr, T.A.; Kälin, W.; Tschan, F. Illegitimate tasks as a source of work stress. Work. Stress 2015, 29, 32-56. [CrossRef]

16. Van Laethem, M.; Beckers, D.G.; de Bloom, J.; Sianoja, M.; Kinnunen, U. Challenge and hindrance demands in relation to self-reported job performance and the role of restoration, sleep quality, and affective rumination. J. Occup. Organ. Psychol. 2019, 92, 225-254. [CrossRef]

17. Kim, M.; Beehr, T.A. Thriving on demand: Challenging work results in employee flourishing through appraisals and resources. Int. J. Stress Manag. 2020, 27, 111-125. [CrossRef]

18. Bakker, A.B.; Sanz-Vergel, A.I. Weekly work engagement and flourishing: The role of hindrance and challenge job demands. J. Vocat. Behav. 2013, 83, 397-409. [CrossRef]

19. Antwi, C.O.; Fan, C.-J.; Aboagye, M.O.; Brobbey, P.; Jababu, Y.; Affum-Osei, E.; Avornyo, P. Job demand stressors and employees' creativity: A within-person approach to dealing with hindrance and challenge stressors at the airport environment. Serv. Ind. J. 2018, 39, 250-278. [CrossRef]

20. Wincent, J.; Örtqvist, D. Examining Positive Performance Implications of Role Stressors by the Indirect Influence of Positive Affect: A Study of New Business Managers. J. Appl. Soc. Psychol. 2011, 41, 699-727. [CrossRef]

21. Albrecht, S.L. Challenge demands, hindrance demands, and psychological need satisfaction. J. Pers. Psychol. 2015, 14, 70-79. [CrossRef]

22. Ahmed, U.; Shah, M.H.; Siddiqui, B.A.; Shah, S.A.; Dahri, A.S.; Qureshi, M.A. Troubling Job Demands at Work: Examining the Deleterious Impact of Workload and Emotional Demands on Work Engagement. Int. J. Acad. Res. Bus. Soc. Sci. 2017, 7. [CrossRef]

23. Donoso, L.M.B.; Demerouti, E.; Hernández, E.G.; Jiménez, B.M.; Carmona-Cobo, I. Positive benefits of caring on nurses' motivation and well-being: A diary study about the role of emotional regulation abilities at work. Int. J. Nurs. Stud. 2015, 52, 804-816. [CrossRef] [PubMed]

24. Parker, S.K. Beyond Motivation: Job and Work Design for Development, Health, Ambidexterity, and More. Annu. Rev. Psychol. 2014, 65, 661-691. [CrossRef]

25. Li, P.; Taris, T.W.; Peeters, M.C. Challenge and hindrance appraisals of job demands: One man's meat, another man's poison? Anxiety Stress Coping 2020, 33, 31-46. [CrossRef] [PubMed]

26. Li, P.; Peeters, M.C.; Taris, T.W.; Zhang, Y. Challenges or Hindrances? Implications of Work Characteristics Appraisals for Employees' Well-Being. 20 September 2020. Available online: https:/ /psyarxiv.com/pjk6v/ (accessed on 15 October 2021).

27. Lazarus, R.S. Emotion and Adaptation; Oxford University Press: New York, NY, USA, 1991.

28. Lazarus, R.S. Cognition and Motivation in Emotion. Am. Psychol. 1991, 46, 352. [CrossRef] [PubMed]

29. Bagozzi, R.P. The Self-Regulation of Attitudes, Intentions, and Behavior. Soc. Psychol. Q. 1992, 55, 178. [CrossRef]

30. Folkman, S.; Lazarus, R.S.; Dunkel-Schetter, C.; DeLongis, A.; Gruen, R.J. Dynamics of a stressful encounter: Cognitive appraisal, coping, and encounter outcomes. J. Personal. Soc. Psychol. 1986, 50, 992. [CrossRef]

31. Magnusson, D.; Stattin, H. Person-context interaction theories. In Handbook of Child Psychology: Theoretical Models of Human Development; Damon, W., Lerner, R.M., Eds.; John Wiley \& Sons Inc: Hoboken, NJ, USA, 1998; pp. 685-759. 
32. Ângelo, R.; Chambel, M.J. The reciprocal relationship between work characteristics and employee burnout and engagement: A longitudinal study of firefighters. Stress Health 2015, 31, 106-114. [CrossRef]

33. Elst, T.V.; Cavents, C.; Daneels, K.; Johannik, K.; Baillien, E.; Broeck, A.V.D.; Godderis, L. Job demands-resources predicting burnout and work engagement among Belgian home health care nurses: A cross-sectional study. Nurs. Outlook 2016, 64, 542-556. [CrossRef]

34. Dicke, T.; Stebner, F.; Linninger, C.; Kunter, M.; Leutner, D. A longitudinal study of teachers' occupational well-being: Applying the job demands-resources model. J. Occup. Health Psychol. 2018, 23, 262-277. [CrossRef]

35. Diener, E.; Thapa, S.; Tay, L. Positive emotions at work. Annu. Rev. Organ. Psychol. Organ. Behav. 2020, 7, 451-477. [CrossRef]

36. Judge, T.A.; Weiss, H.M.; Kammeyer-Mueller, J.D.; Hulin, C.L. Job attitudes, job satisfaction, and job affect: A century of continuity and of change. J. Appl. Psychol. 2017, 102, 356-374. [CrossRef] [PubMed]

37. Oswald, A.J.; Proto, E.; Sgroi, D. Happiness and Productivity. J. Labor Econ. 2015, 33, 789-822. [CrossRef]

38. Langley, S. Facilitating Positive Emotions for Greater Creativity and Innovation. In Individual, Relational, and Contextual Dynamics of Emotions; Emerald Publishing Limited: Bingley, UK, 2018; pp. 259-270.

39. Costantini, A.; Sartori, R. The Intertwined Relationship Between Job Crafting, Work-Related Positive Emotions, and Work Engagement. Evidence from a Positive Psychology Intervention Study. Open Psychol. J. 2018, 11, 210-221. [CrossRef]

40. Van Doorn, E.A.; Heerdink, M.W.; Van Kleef, G. Emotion and the construal of social situations: Inferences of cooperation versus competition from expressions of anger, happiness, and disappointment. Cogn. Emot. 2012, 26, 442-461. [CrossRef]

41. Hu, X.; Kaplan, S. Is "feeling good" good enough? Differentiating discrete positive emotions at work. J. Organ. Behav. 2015, 36, 39-58. [CrossRef]

42. Vittersø, J. Functional well-being: Happiness as feelings, evaluations, and functioning. In Oxford Handbook of Happiness; Oxford Univeristy Press: Oxford, UK, 2013; pp. 227-244.

43. Vittersø, J. The feeling of excellent functioning: Hedonic and eudaimonic emotions. In Handbook of Eudaimonic Well-Being; Springer: Berlin/Heidelberg, Germany, 2016; pp. 253-276.

44. Stone, A.A.; Schwartz, J.E.; Schkade, D.; Schwarz, N.; Krueger, A.; Kahneman, D. A population approach to the study of emotion: Diurnal rhythms of a working day examined with the day reconstruction method. Emotion 2006, 6, 139-149. [CrossRef] [PubMed]

45. SStraume, L.V.; Vittersø, J. Happiness, inspiration and the fully functioning person: Separating hedonic and eudaimonic well-being in the workplace. J. Posit. Psychol. 2012, 7, 387-398. [CrossRef]

46. Thorsteinsen, K.; Vittersø, J. Striving for wellbeing: The different roles of hedonia and eudaimonia in goal pursuit and goal achievement. Int. J. Wellbeing 2018, 8, 89-109. [CrossRef]

47. Rogala, A.; Cieslak, R. Positive Emotions at Work and Job Crafting: Results from Two Prospective Studies. Front. Psychol. 2019, 10. [CrossRef]

48. Kahneman, D.; Tversky, A. Choices, Values, and Frames; Cambridge University Press: New York, NY, USA, 2000.

49. Wilks, T. The Use of Vignettes in Qualitative Research into Social Work Values. Qual. Soc. Work. Res. Pr. 2004, 3, 78-87. [CrossRef]

50. Atzmüller, C.; Steiner, P.M. Experimental Vignette Studies in Survey Research. Methodology 2010, 6, 128-138. [CrossRef]

51. Hughes, R.; Huby, M. The application of vignettes in social and nursing research. J. Adv. Nurs. 2002, 37, 382-386. [CrossRef] [PubMed]

52. Muthén, L.K.; Muthén, B.O. Mplus User's Guide, 8th ed.; Muthén \& Muthen: Los Angeles, CA, USA, $1998-2017$.

53. Horn, J.L. A rationale and test for the number of factors in factor analysis. Psychometrika 1965, 30, 179-185. [CrossRef]

54. Vittersø, J.; Oelmann, H.I.; Wang, A.L. Life Satisfaction is not a Balanced Estimator of the Good Life: Evidence from Reaction Time Measures and Self-Reported Emotions. J. Happiness Stud. 2007, 10, 1-17. [CrossRef]

55. Tadić, M.; Bakker, A.B.; Oerlemans, W.G. Challenge versus hindrance job demands and well-being: A diary study on the moderating role of job resources. J. Occup. Organ. Psychol. 2015, 88, 702-725. [CrossRef]

56. Searle, B.J.; Tuckey, M.R. Differentiating challenge, hindrance, and threat in the stress process. In The Routledge Companion to Wellbeing at Work; Routledge: New York, NY, USA, 2017; pp. 25-36.

57. Broetje, S.; Jenny, G.J.; Bauer, G.F. The Key Job Demands and Resources of Nursing Staff: An Integrative Review of Reviews. Front. Psychol. 2020, 11. [CrossRef]

58. Baethge, A.; Vahle-Hinz, T.; Schulte-Braucks, J.; Van Dick, R. A matter of time? Challenging and hindering effects of time pressure on work engagement. Work. Stress 2017, 32, 228-247. [CrossRef]

59. Ariely, D.; Kamenica, E.; Prelec, D. Man's search for meaning: The case of Legos. J. Econ. Behav. Organ. 2008, 67, 671-677. [CrossRef]

60. Brody, L.R.; Hall, J.A. Gender and emotion in context. Handb. Emot. 2008, 3, 395-408.

61. Eagly, A.H. 4 Sex Differences in Social Behavior: A Social-Role Interpretation; Lawrence Erlbaum: Hillsdale, NJ, USA, 1987.

62. Weedon, C. Feminist Practice and Poststructuralist Theory; Oxford: Blackwell, UK, 1997.

63. Biernat, M. Toward a Broader View of Social Stereotyping. Am. Psychol. 2003, 58, 1019-1027. [CrossRef] [PubMed]

64. Cheng, M.-L.; Tseng, Y.-H.; Hodges, E.; Chou, F.-H. Lived Experiences of Novice Male Nurses in Taiwan. J. Transcult. Nurs. 2016, 29, 46-53. [CrossRef] [PubMed]

65. Statistisk Sentralbyrå. 12546: Lønnstakere Med Helse- og Sosialfaglig Utdanning. Available online: https://www.ssb.no/ statbank/table/12546/tableViewLayout1/ (accessed on 6 June 2021). 
66. Statistisk Sentralbyrå. 12542: Lønnstakere. 4. Kvartal, Etter Kjønn, Statistikkvariabel, år og Yrke. Available online: https: //www.ssb.no/statbank/table/12542/tableViewLayout1/ (accessed on 2 June 2021).

67. McDougall, G.H.; Levesque, T. Customer satisfaction with services: Putting perceived value into the equation. J. Serv. Mark. 2000, 14, 392-410. [CrossRef] 